\title{
Needlescopic surgery for large umbilical hernia in a patient with morbid obesity using intraperitoneal onlay mesh with fascial defect closure: a case report
}

\author{
Hisataka Fujiwara ${ }^{1 *}\left(\mathbb{0}\right.$, Takayuki Suto $^{1}$, Akira Umemura ${ }^{2}$, Yota Tanahashi $^{1}$, Satoshi Amano ${ }^{1}$, Kenichiro Ikeda $^{3}$, \\ Kazuho Harada ${ }^{4}$ and Akira Sasaki ${ }^{2}$
}

\begin{abstract}
Background: The European and American guidelines recommend that symptomatic umbilical hernias (UHs) are repaired using an open approach with a preperitoneal flat mesh. However, the standard treatment procedure for large UH in patients with extreme obesity is yet to be established. Here, we present the first case of a patient with morbid obesity undergoing laparoscopic UH repair using needlescopic instruments and an intraperitoneal onlay mesh plus repair (IPOM plus).

Case presentation: A 29-year-old man, who was classified as morbidly obese (body mass index, $36.7 \mathrm{~kg} / \mathrm{m}^{2}$ ) noticed a reducible nontender mass in the umbilical region and was subsequently diagnosed with an UH, with a diameter of $4 \mathrm{~cm}$. Laparoscopic IPOM plus repair was planned using a needlescopic method for a large UH in the patient with morbid obesity. A 3-mm rigid laparoscope was mainly used in the procedure. After a 12-mm trocar and two 3-mm trocars were inserted, fascial defect closure was performed using intracorporeal suturing with 0 monofilament polypropylene threads. Then, IPOM was performed laparoscopically using an 11.4-cm round mesh coated with collagen to prevent adhesions. The operative time and blood loss were $57 \mathrm{~min}$ and $1 \mathrm{~g}$, respectively. The postoperative course was uneventful.
\end{abstract}

Conclusions: Reduced-port laparoscopic surgery using needlescopic instruments and an IPOM plus technique is a minimally invasive and convenient combination option for large UH in a patient with morbid obesity.

Keywords: Umbilical hernia, Reduced-port surgery, Laparoscopic surgery, Needlescopic surgery, Intraperitoneal onlay mesh, IPOM plus, Obesity

\section{Background}

Umbilical hernia (UH) in adults is a common condition in noninguinal abdominal wall hernias, and increased body mass index (BMI) is associated with higher prevalence and increased risk of incarceration [1]. UHs are prone to

\footnotetext{
*Correspondence: hisataka-ga-ri-@@angel.odn.ne.jp

1 Surgery Division, Morioka Municipal Hospital, 5-15-1 Motomiya,

Morioka, Iwate 020-0866, Japan

Full list of author information is available at the end of the article
}

incarceration and continue to enlarge if untreated; thus, prompt repair is advised.

Guidelines for the treatment of umbilical and epigastric hernias from the European Hernia Society (EHS) and Americas Hernia Society (AHS) recommend that symptomatic umbilical and epigastric hernias are repaired using an open approach with a preperitoneal flat mesh $[2,3]$. Conversely, the guidelines also provided an official statement on the benefit of laparoscopic repair for larger $(>4 \mathrm{~cm}$ in diameter) UHs or patients with increased risk of wound infection $[2,4,5]$. Moreover, intraperitoneal 
onlay mesh (IPOM) with fascial defect closure (IPOM plus) reinforcement in laparoscopic ventral and incisional hernia repair has been introduced and reported in the "Guidelines for laparoscopic treatment of ventral and incisional abdominal wall hernias" published by the International Endohernia Society (IEHS) in 2014 [6]. Based on the guidelines, a laparoscopic approach using IPOM plus may be considered in the repair of large UHs in patients with obesity.

However, minimally invasive surgery has been characterized by the increased development of smaller operative instruments. Recently, reduced-port surgery has become a focus of minimally invasive laparoscopic surgical approaches and has been developed worldwide for various abdominal procedures [7-9]. Reduced-port surgery can be divided into two techniques: needlescopic and single-incision port laparoscopic surgeries. It is known that a single-incision laparoscopic approach increases the risk of hernia formation and is not a naturally ergonomic technique, especially in patients with severe obesity [10]. Therefore, the conventional laparoscopic UH repair usually requires several ports. The needlescopic technique is safely applicable to laparoscopic hernia repair by minimal dissection without the restriction of operation compared with the single-incision laparoscopic approach.

The present systematic review included only Englishlanguage articles in the PubMed database identified using the keywords "umbilical hernia", a combination of "umbilical hernia" and "laparoscopic surgery", and a combination of "umbilical hernia" and "reduced-port surgery". No reports to date have described reduced-port surgery for UH using IPOM plus. To the best of our knowledge, the needlescopic approach using one 12- $\mathrm{mm}$ trocar and two 3- $\mathrm{mm}$ trocars for UH repair in patient with morbid obesity is extremely rare.

Herein, we report the use of the IPOM plus method combined with reduced-port surgery to safely treat a large UH in a patient with morbid obesity with a BMI of $36.7 \mathrm{~kg} / \mathrm{m}^{2}$, along with some literature review.

\section{Case presentation}

A 29-year-old man was referred to our hospital for further evaluation. He had upper abdominal discomfort, intermittent periumbilical pain, and nausea the previous day. Medical history included morbid obesity (height, $180 \mathrm{~cm}$; weight, $119 \mathrm{~kg}$; BMI, $36.7 \mathrm{~kg} / \mathrm{m}^{2}$ ), diabetes, and hyperuricemia. He noticed a reducible nontender mass in the umbilical region a few years before. Physical examination revealed no abdominal distension and tenderness but a visible and palpable mass with an approximately 4-cm hernial orifice in the umbilical region (Fig. 1a). Contrast-enhanced computed tomography also showed $\mathrm{UH}$ with part of the greater omentum entering the

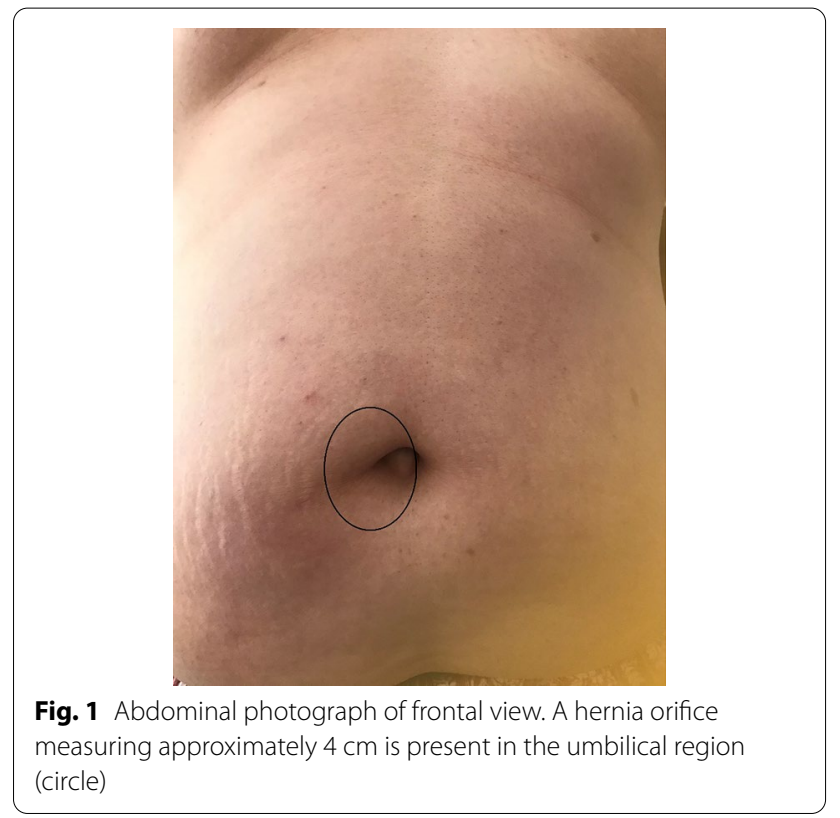

hernial orifice, but there was no ascites or small bowel obstruction (Fig. 2a, b).

The patient agreed to undergo laparoscopic UH repair. We decided to perform a laparoscopic IPOM plus method to reduce the risk of recurrence and planned to conduct reduced-port laparoscopic surgery using a 12-mm trocar and two 3-mm trocars to minimize the surgical wound.

With the patient in the supine position under general anesthesia, we inserted three trocars (Fig. 3). A 12-mm trocar (ENDOPATH ${ }^{\circledR}$ XCEL; Ethicon, New Brunswick, $\mathrm{NJ}$, USA) was placed on the left hypochondrium region using optical access. After establishing pneumoperitoneum using the insufflation of carbon dioxide up to a pressure of $12 \mathrm{mmHg}$, two 3-mm trocars were inserted into the epigastric region and left lateral side of the abdomen. A 3-mm rigid laparoscope (KARL STORZ NDTec $\mathrm{GmbH}$, Germany) was mainly inserted into the epigastric region via the $3-\mathrm{mm}$ trocar, and surgery was performed using the other two trocars $(12-\mathrm{mm}$ trocar and 3-mm trocar in the left lateral side of the abdomen) as working ports for the operator.

The hernia contents were not observed in the UH, and the margins of the hernial defect were clearly defined under the insufflation pressure of $12 \mathrm{mmHg}$ (Fig. 4a). To prevent an overestimation of the defect size, insufflation pressure was reduced to $6 \mathrm{mmHg}$ at the time of measurement. The hernial orifice was round with a $5-\mathrm{cm}$ diameter (Fig. 4b). First, using the 12-mm trocar as a working port for a 5-mm needle holder, the hernial orifice was closed intracorporeally by simple interrupted 

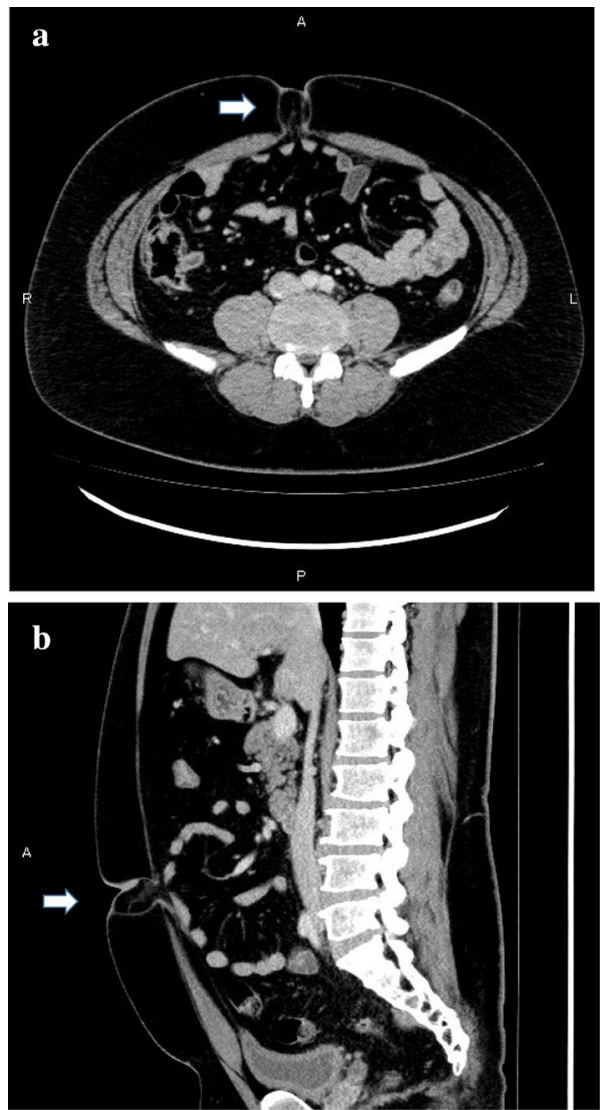

Fig. 2 Sections of enhanced abdominal computed tomography. The greater omentum seems to be incarcerated (arrow). a Horizontal section. b Coronal section

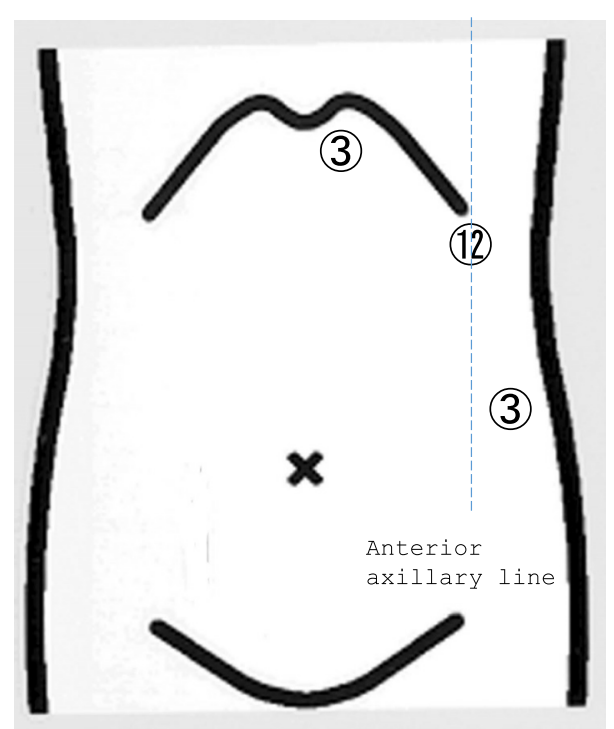

Fig. 3 Trocar placement sutures with 0 monofilament polypropylene threads (Surgipro $^{\mathrm{TM}}$; Medtronic Inc., Minneapolis, MN, USA) under insufflation pressure of $6-8 \mathrm{mmHg}$ (Fig. 4c). Five stitches were required to close the hernial orifice. Then, an 11.4-cm round mesh with an attachment was selected to help facilitate deployment and placement and coated with collagen to prevent adhesions (Ventralight ${ }^{\mathrm{TM}} \mathrm{ST}$ Mesh with Echo $2^{\mathrm{TM}}$; Bard, Warwick, RI, USA). Next, the mesh was introduced into the abdominal cavity using a 12-mm trocar and placed under the hernial orifice, and the hoisting suture was retrieved through the center of the closure line of the hernial defect and hoisted to the abdominal wall using an EndoClose ${ }^{\mathrm{TM}}$ (Medtronic Inc.) (Fig. 4d). An overlap of at least 3- to 5-cm-mesh overlap for the closure line of the hernial orifice was inspected and fixed by a double-crown technique using a mesh fixation device (AbsorbaTack ${ }^{\mathrm{TM}}$; Medtronic Inc.) (Fig. 4e). The port-site wound of the inserted 12-mm trocar was closed by two-stitch sutures with absorbable surgical sutures (0 Monosyn ${ }^{\circledR}$; B. Braun, Melsungen, Germany) using an EndoClose $^{\mathrm{TM}}$ (Medtronic Inc.). Moreover, skin incisions were closed by dermal suturing with absorbable surgical sutures. Lidocaine hydrochloride (1\%) was inserted into the trocar sites at the end of the surgery. The postoperative wounds are shown in Fig. 5.

The operative time and blood loss were $57 \mathrm{~min}$ and $1 \mathrm{~g}$, respectively. The patient received celecoxib $400 \mathrm{mg} /$ day orally for 4 days from the day of the surgery and sometimes needed additional analgesics for postoperative abdominal pain, which is not the port site but mesh fixation region. The postoperative course was uneventful, and the patient was discharged on postoperative day 3 .

\section{Discussion}

UHs in adults are common conditions of noninguinal abdominal wall hernias. The current view is that patients with asymptomatic UH and acutely incarcerated UH should undergo surgery to avoid postoperative complications.

Since the introduction by LeBlanc in 1993 [11], laparoscopic ventral and incisional hernia repair has gained popularity globally. Additionally, the recent case series and reviews with long-term follow-up proved that laparoscopic ventral and incisional hernia repair had advantages in terms of lower recurrence and wound infection rates compared with open ventral and incisional hernia repair [2-6].

The guidelines from the EHS and AHS also recommend a laparoscopic mesh-based repair approach for a large UH or in patients with an increased risk of wound infection [2]. Thus, the laparoscopic hernia repair has a great advantage over the open surgery, that is to say, the smaller wound size, the better. Generally, obesity is 


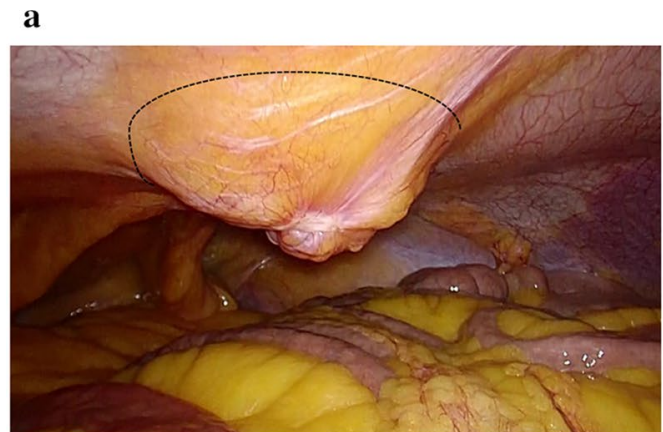

b

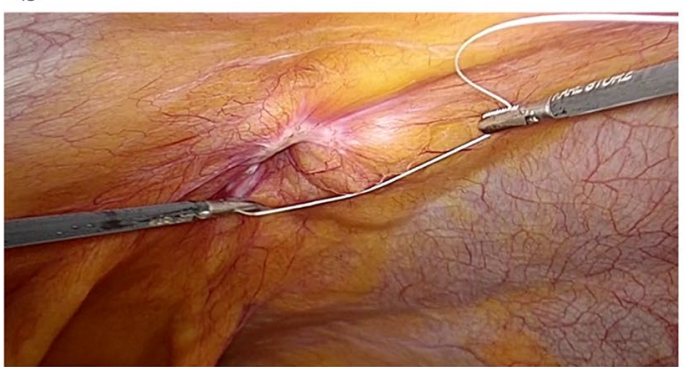

e

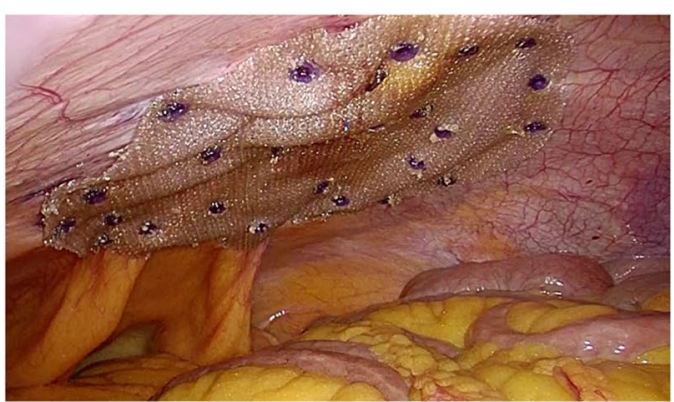

Fig. 4 Intracorporeal procedure for umbilical hernia. a Palpation of the hernial orifice (circle). $\mathbf{b}$ Measurement of the hernial orifice. $\mathbf{c}$ Closure of the

hernial orifice with simple interrupted sutures. $\mathbf{d}$ Temporarily securing the mesh with an attachment to help facilitate deployment. e Securing the mesh using the double-crown technique

known to be associated with increased wound morbidity after primary hernia repair [12,13]. Furthermore, obesity and wound infection increase the recurrence rate. Our patient had morbid obesity (BMI, $36.7 \mathrm{~kg} / \mathrm{m}^{2}$ ) and an increased risk of a large hernial orifice $(>4 \mathrm{~cm})$. Therefore, the decision was made to perform a laparoscopic mesh-based repair approach for accurate measurement of the hernial defect size and reduce the risk of surgical site infection. It is also well known that trocar-site hernia was associated with obesity, wound infection, and the use of $>10-\mathrm{mm}$ trocar [14]. Compared with the open access technique, direct trocar insertion was considered superior in terms of port-site hernia, infection, and pain [7, 15]. Thus, we used 3-mm instead of 5-mm trocars mainly. However, we had to select a $12-\mathrm{mm}$ trocar to introduce the mesh, which is bifaceted, polypropylene, and expanded polytetrafluoroethylene, into the abdominal

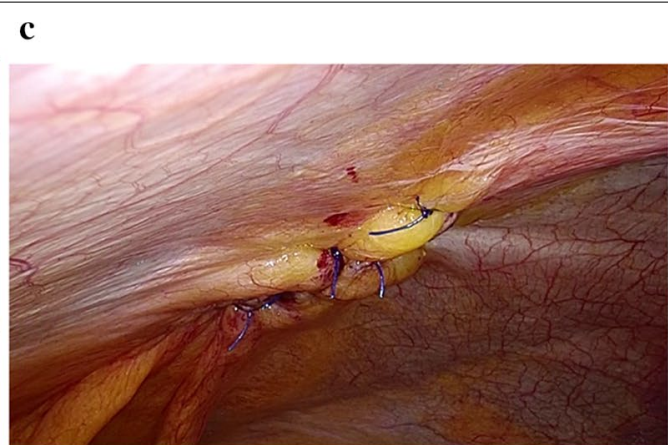

d

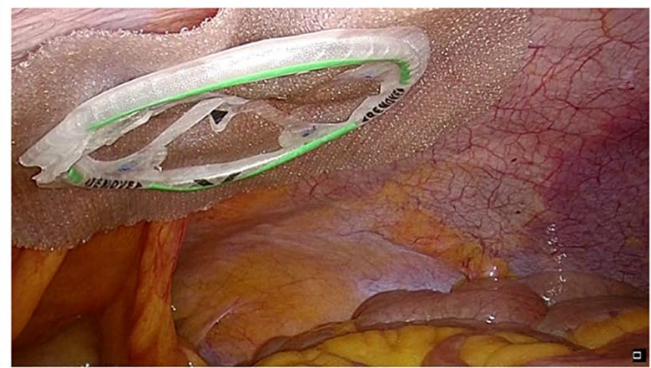

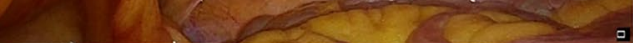

cavity, because few meshes are introduced using $<10-\mathrm{mm}$ trocar. To minimize the surgical wound, we planned to place the $12-\mathrm{mm}$ trocar using visually guided insertion.

Furthermore, we planned to perform reduced-port surgery by placing two $3-\mathrm{mm}$ trocars and using a $3-\mathrm{mm}$ rigid laparoscope. With regard to reduced-port surgery, the single-incision and needlescopic approach has become an increasingly important form of several laparoscopic surgical conditions [8-10], due to the expected benefits of minimally invasive surgery, including less pain and quick recovery from fewer scars and better cosmetic satisfaction. However, the guidelines from the IEHS did not provide an official statement on the benefit of reducedport technique in the section of key points of the technique [7]. A single-incision laparoscopic approach is an inconvenient ergonomic operation and increases the risk of hernia formation, especially in patients with severe 


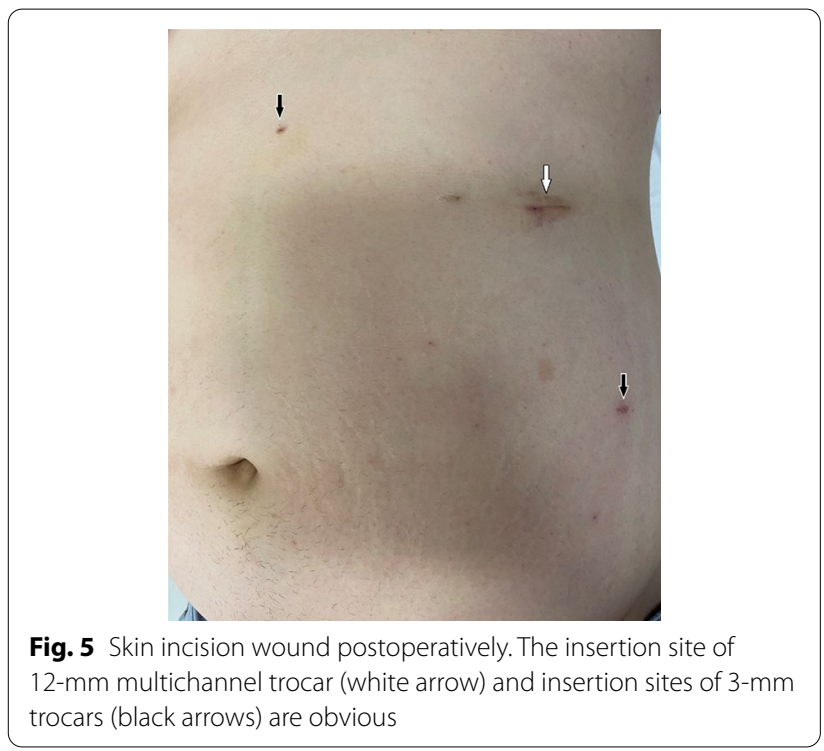

obesity [10]. Meanwhile, a needlescopic approach is a convenient method because it can keep the traditional laparoscopic principle of triangulation. And the 3-mm trocar requires no port-site closure. This point is also beneficial in cosmetic and postoperative pain aspects $[16,17]$. Moreover, the incidence of trocar-site hernias is rare in cases with $<10-\mathrm{mm}$ trocar sites, especially with 3 -mm trocar sites $[18,19]$. However, there are some points of caution. The needlescope provides poorer resolution image compared to larger scopes. The small jaws and supple fine shafts of the needlescopic instruments cause difficulties in surgical procedure, especially in cases of severe adhesion or obesity. To avoid the difficulties above, it is important to choose and change the site of the needlescope between the inserted ports according the requirements of the case.

Concerning the IPOM plus technique [7], there are a few high-quality studies on primary ventral hernias focusing specifically on defect closure. Suwa et al. [20] revealed that the recurrence rate, incidence rate of seroma formation, and incidence rate of mesh bulging in the IPOM plus technique for ventral and incisional hernias were $0-7.7 \%, 0-11.4 \%$, and $0 \%$, respectively. Moreover, Christoffersen et al. [21] reported that the recurrence rate after 2 years and seroma formation after 30 days were $3-17 \%$ and $10-33 \%$, respectively. In the absence of abdominal wall tension during fascial closure, an additional fascial closure technique seems to decrease seroma formation, mesh bulging, and recurrence.

In the IPOM plus technique, various fascial closure methods are classified into extracorporeal or intracorporeal suture methods. We have generally selected the intracorporeal suture method, which is a more difficult procedure, because extracorporeal suture methods seem to increase the risk of skin infection by many stabs on the skin. Conversely, if the IPOM plus technique is selected, a landmark for the overlap of the mesh was divided into two groups: according to the border of the original fascial defect or after the closure of the defect by sutures. Based on the guidelines, a large overlap is recommended for large hernias [3]. Suwa et al. [20] revealed that the recurrence rate showed no significant difference between the overlap selected based on the original fascial defect and after closure line. If the mesh size is selected based on the closure line, an overlap of $>5 \mathrm{~cm}$ occurs more easily, especially for a transverse diameter. We have considered that a reduction in the recurrence rate could be expected by selecting mesh size based on the closure line.

We have presented the first case of a patient with morbid obesity who underwent reduced-port laparoscopic $\mathrm{UH}$ repair employing an IPOM plus technique.

We have considered that employing the IPOM plus technique may potentially reduce the recurrence rate of various umbilical or ventral hernias. Moreover, reducedport laparoscopic surgery using the needlescopic technique for a patient with morbid obesity decreased the risk of port-site hernia and surgical site infection without affecting the safety or quality of the procedure.

In conclusion, this case has followed a satisfactory course without any troubles, whereas it is obvious that the difficulty level of this surgery depends on the adhesion in the abdominal cavity and the size/position of the hernia orifice. Our successful cases, however, strongly suggests that needlescopic surgery has the potential to play major role on the $\mathrm{UH}$ repair in the patients with morbid obesity.

\section{Abbreviations}

UH: Umbilical hernia; UHs: Umbilical hernias; EHS: European Hernia Society; AHS: American Hernia Society; IPOM: Intraperitoneal onlay mesh; IPOM plus: Intraperitoneal onlay mesh with fascial defect closure; IEHS: International Endohernia Society; BMI: Body mass index.

\section{Acknowledgements}

Not applicable

\section{Authors' contributions}

$\mathrm{FH}, \mathrm{ST}$, and UA performed the data analysis and surgical procedures. $\mathrm{FH}$, $\mathrm{YT}$, and SA contributed to the patient's care. FH, YT, SA, and KI collected the patient's data. FH drafted the manuscript, and ST, KI, KH and SA performed a dedicated review and discussion. All authors read and approved the final manuscript.

\section{Funding \\ None.}

Availability of data and materials Not applicable.

Ethics approval and consent to participate

Not applicable. 


\section{Consent for publication}

Written informed consent was obtained from the patient for publication of this case report and any accompanying images.

\section{Competing interests}

The authors declare that they have no competing interests.

\section{Author details}

1 Surgery Division, Morioka Municipal Hospital, 5-15-1 Motomiya, Morioka, I wate 020-0866, Japan. ${ }^{2}$ Department of Surgery, School of Medicine, Iwate Medical University, 1-1-1 Idaidori, Yahaba-cho, Iwate 028-3695, Japan. ${ }^{3}$ Ikedalin, 5-18 Sakaida, Morioka, Iwate 020-0041, Japan. ${ }^{4}$ Anesthesia Division, Morioka Municipal Hospital, 5-15-1 Motomiya, Morioka, Iwate 020-0866, Japan.

Received: 12 June 2020 Accepted: 19 September 2020

Published online: 01 October 2020

\section{References}

1. Lau B, Kim H, Haigh Pl, Tejirian T. Obesity increases the odds of acquiring and incarcerating noninguinal abdominal wall hernias. Am Surg. 2012;78(10):1118-21.

2. Henriksen NA, Montgomery A, Kaufmann R, Berrevoet F, East B, Fischer J, Hope W, Klassen D, Lorenz R, Renard Y, Garcia Urena MA, Simons MP. European and Americas Hernia Societies (EHS and AHS): guidelines for treatment of umbilical and epigastric hernias from the European Hernia Society and Americas Hernia Society. Br J Surg. 2020;107(3):171-90. https ://doi.org/10.1002/bjs.11489.

3. Bisgaard T, Kaufmann R, Christoffersen MW, Strandfelt P, Gluud LL. Lower risk of recurrence after mesh repair versus non-mesh sutured repair in open umbilical hernia repair: a systematic review and meta-analysis of randomized controlled trials. Scand J Surg. 2019;108(3):187-93. https:// doi.org/10.1177/1457496918812208.

4. Sauerland S, Walgenbach M, Habermalz B, Seiler CM, Miserez M. Laparoscopic versus open surgical techniques for ventral or incisional hernia repair. Cochrane Database Syst Rev. 2011;16(3):7781. https://doi. org/10.1002/14651858.CD007781.pub2.

5. Zhang Y, Zhou H, Chai Y, Cao C, Jin K, Hu Z. Laparoscopic versus open incisional and ventral hernia repair: a systematic review and metaanalysis. World J Surg. 2014;38(9):2233-40. https://doi.org/10.1007/s0026 8-014-2578-z.

6. Bittner R, Bingener-Casey J, Dietz U, Fabian M, Ferzli GS, Fortelny RH, Köckerling F, Kukleta J, Leblanc K, Lomanto D, Misra MC, Bansal VK, Morales-Conde S, Ramshaw B, Reinpold W, Rim S, Rohr M, Schrittwieser R, Simon T, Smietanski M, Stechemesser B, Timoney M, Chowbey P. Guidelines for laparoscopic treatment of ventral and incisional abdominal wall hernias (International Endohernia Society (IEHS)-Part 1). Surg Endosc. 2014;28(1):2-29. https://doi.org/10.1007/s00464-013-3170-6.

7. Umemura A, Suto T, Fujiwara H, Nakamura S, Endo F, Sasaki A. Retrospective case-matched study between reduced port laparoscopic rectopexy and conventional laparoscopic rectopexy for rectal prolapse. J Minim Access Surg. 2019;15(4):316-9. https://doi.org/10.4103/jmas. JMAS_100_18.

8. Umemura A, Suto T, Nakamura S, Fujiwara H, Endo F, Nitta H, Takahara T, Sasaki A. Comparison of single-incision laparoscopic cholecystectomy versus needlescopic cholecystectomy: A single institutional randomized clinical trial. Dig Surg. 2019;36(1):53-8. https://doi.org/10.1159/00048 6455.

9. Sasaki A, Ogawa M, Tono C, Obara S, Hosoi N, Wakabayashi G. Single-port versus multiport laparoscopic cholecystectomy: a prospective randomized clinical trial. Surg Laparosc Endosc Percutan Tech. 2012;22(5):3969. https://doi.org/10.1097/SLE.0b013e3182631a9a.

10. Guzmán ARC, Morandeira-Rivas AJ, Herrero-Bogajo ML, Moreno-Sanz C. Incidence and risk factors of incisional hernia after single-incision endoscopic surgery. Laparoendosc Adv Surg Tech A. 2020;30(3):251-5. https:// doi.org/10.1089/lap.2019.0728.

11. LeBlanc KA, Booth WV. Laparoscopic repair of incisional abdominal hernias using expanded polytetrafluoroethylene: Preliminary findings. Surg Laparosc Endosc. 1993;3(1):39-41.

12. Martindale RG, Deveney CW. Preoperative risk reduction: strategies to optimize outcomes. Surg Clin North Am. 2013;93(5):1041-55. https://doi. org/10.1016/j.suc.2013.06.015.

13. Köhler G, Luketina RR, Emmanuel K. Sutured repair of primary small umbilical and epigastric hernias: concomitant rectus diastasis is a significant risk factor for recurrence. World J Surg. 2015;39(1):121-6. https://doi. org/10.1007/s00268-014-2765-y.

14. Nofal MN, Yousef AJ, Hamdan FF, Oudat AH. Characteristics of trocar site hernia after laparoscopic cholecystectomy. Sci Rep. 2020;10(1):2868. https ://doi.org/10.1038/s41598-020-59721-w.

15. Kaistha S, Kumar A, Gangavatiker R, Br S, Sisodiya N. Laparoscopic access: direct trocar insertion versus open technique. J Laparoendosc Adv Surg Tech A. 2019;29(4):489-94. https://doi.org/10.1089/lap.2018.0408.

16. Tagaya N, Kubota K. Reevaluation of needlescopic surgery. Surg Endosc. 2012;26(1):137-43. https://doi.org/10.1007/s00464-011-1839-2.

17. Wada H, Kimura T, Kawabe A, Sato M, Miyaki Y, Tochikubo J, Inamori K, Shiiya N. Laparoscopic transabdominal preperitoneal inguinal hernia repair using needlescopic instruments: a 15-year, single-center experience in 317 patients. Surg Endosc. 2012;26(7):1898-902. https://doi.org/10.1007/ s00464-011-2122-2

18. Backman T, Arnbjörnsson E, Kullendorff CM. Omentum herniation at a 2-mm trocar site. J Laparoendosc Adv Surg Tech A. 2005;15(1):87-8. https ://doi.org/10.1089/lap.2005.15.87

19. Angeliki C, Samer A, Antonios M, Theodosios SP. Richter's hernia in a 5-mm trocar site. SAGE Open Med Case Rep. 2019;7:1-4. https://doi. org/10.1177/2050313X18823413.

20. Suwa K, Okamoto T, Yanaga K. Closure versus non-closure of fascial defects in laparoscopic ventral and incisional hernia repairs: a review of the literature. Surg Today. 2016;46(7):764-73. https://doi.org/10.1007/ s00595-015-1219-y.

21. Christoffersen MW, Westen M, Rosenberg J, Helgstrand F, Bisgaard T. Closure of the fascial defect during laparoscopic umbilical hernia repair: a randomized clinical trial. Br J Surg. 2020;107(3):200-8. https://doi. org/10.1002/bjs.11490.

\section{Publisher's Note}

Springer Nature remains neutral with regard to jurisdictional claims in published maps and institutional affiliations. 